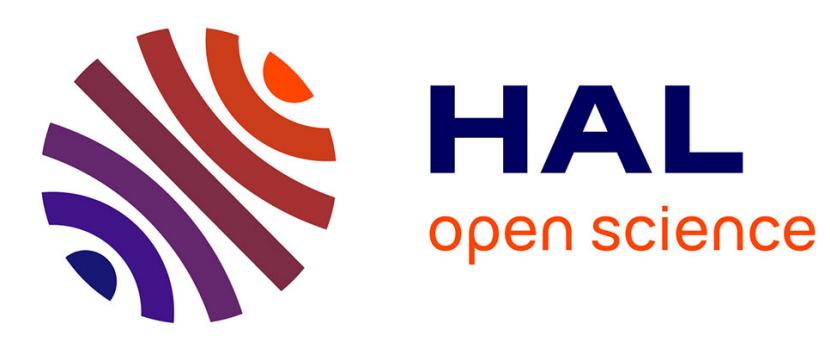

\title{
Study of interaction fidelity for two viewpoint changing techniques in a virtual biopsy trainer
}

\author{
Aylen Ricca, Amine Chellali, Samir Otmane
}

\section{To cite this version:}

Aylen Ricca, Amine Chellali, Samir Otmane. Study of interaction fidelity for two viewpoint changing techniques in a virtual biopsy trainer. 19th IEEE Virtual Reality Conference (VR 2017), Mar 2017, Los Angeles, CA, United States. pp.227-228, 10.1109/VR.2017.7892259 . hal-01524543

\section{HAL Id: hal-01524543 \\ https://hal.science/hal-01524543}

Submitted on 19 May 2017

HAL is a multi-disciplinary open access archive for the deposit and dissemination of scientific research documents, whether they are published or not. The documents may come from teaching and research institutions in France or abroad, or from public or private research centers.
L'archive ouverte pluridisciplinaire HAL, est destinée au dépôt et à la diffusion de documents scientifiques de niveau recherche, publiés ou non, émanant des établissements d'enseignement et de recherche français ou étrangers, des laboratoires publics ou privés. 


\section{Study of Interaction Fidelity for Two Viewpoint Changing Techniques in a Virtual Biopsy Trainer}

\author{
Aylen Ricca*
}

\author{
Amine Chellali* \\ *IBISC Laboratory, University of Evry, France
}

Samir Otmane*

decomposes interaction fidelity into three main components: Biomechanical Symmetry (body movements), Control symmetry and System appropriateness (suitability of the technique). However, it has never been used to assess VR surgical simulators.

Following an iterative design process, we have previously developed a prototype of a biopsy VR simulator [7]. Biopsy is a minimally invasive surgical procedure that consists of inserting a needle into the human body to reach a target tissue (e.g. a tumor). This procedure is performed with a limited real time visual feedback to guide the manipulation of the needle. Therefore, the accuracy of this task requires high haptic and 3D spatial abilities. The evaluation of the previous prototype by novices and expert clinicians pointed out the limited navigation possibilities within the virtual environment (VE). In this paper, we present a new iteration that aims to design navigation techniques (i.e. changing user's view point) for the system with a specific focus on studying their interaction fidelity aspects using FIFA. A user study is also presented to compare these techniques.

\section{Design and DeVelopment of the VR Trainer}

For our system, two distinct navigation techniques are proposed [9]. These techniques correspond to existing metaphors usually used for navigation inside VE but which have different levels of interaction fidelity.

\subsection{Head-Tracking Based Technique}

This technique is based on tracking the user's head position and to update the virtual camera position in the simulator accordingly. It allows the user to change his point of view freely within the scene by simply moving his/her head, similar to what the clinician experiences when performing the real-world task.

\subsection{Touch-Based Technique}

This technique is inspired by the fact that clinicians use their nondominant hand as a local reference frame when performing the needle insertion task. This is related to the asymmetrical bimanual model [2] which argues that the non-dominant hand serves as a frame of reference for tasks performed using the dominant hand. Two hand gestures are proposed, dragging to rotate the scene in the opposite direction of the movement, and pinch to zoom in/out.

\subsection{Application of FIFA on the Navigation Techniques}

Head-tracking (HT) technique has a higher biomechanical symmetry than touch-based (TB) since body movements involved and forces applied are those of human's real navigation. Regarding control symmetry characteristics, both techniques have a high-fidelity dimensional symmetry, allowing controlling virtual camera's position. However, while user's movement is mapped to the same movement of the virtual camera for HT technique (high transfer function symmetry level), TB navigation requires converting finger movements to a delta angle (rotations) or to a displacement (zoom) prior to updating the camera position (lowlevel approach). Termination symmetry in natural navigation is identically reproduced in $\mathrm{HT}$, but requires taking off the finger 
from the screen for TB (lower level). Finally, TB navigation has a lower level of system appropriateness because gesture detection determines a higher latency and requires a touch input device.

As a whole, HT is classified as a high-fidelity interaction technique and TB as a moderate-fidelity interaction technique.

\section{USER STUdy}

To compare the two techniques performance, a user study was conducted using the newly developed prototype (Figure 1).

Fourteen naïve subjects with a limited experience with needle insertion tasks participated in this study. The study followed a within-subject design with one factor (navigation technique) with two levels: head-tracking (HT) and touch-based (TB) techniques.
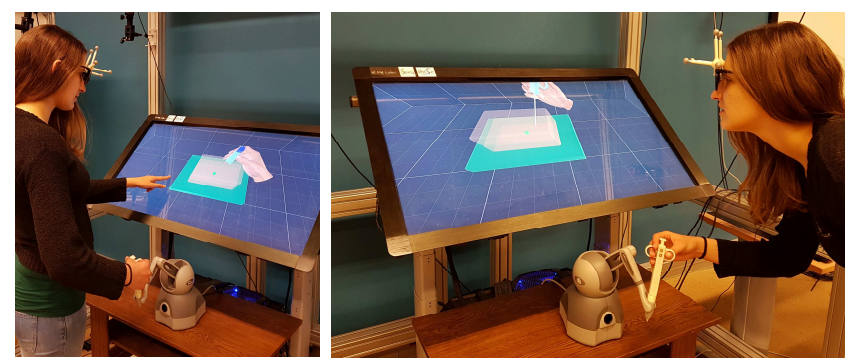

Figure 1: (left) Touch-Based and (right) Head-tracking techniques.

\section{Results}

\subsection{Objective Measures}

The paired-samples t-test showed a significant main effect of the technique on the completion time $\left(\mathrm{t}_{13}=2.25, \mathrm{p}=0.04\right)$. The participants performed the task faster in the HT condition. In addition, although participants were more accurate in the HT condition, the paired-samples t-test showed no significant effect of the technique on the accuracy $\left(\mathrm{t}_{13}=0.56, \mathrm{p}=0.58\right)$.

For a more in depth analysis, accuracy was compared for each axis separately. One-way ANOVAs show no significant effect of axis $\left(\mathrm{F}_{(2,39)}=2.38, \mathrm{p}=0.10\right)$ on the accuracy for HT condition and a significant effect of axis $\left(\mathrm{F}_{(2,39)}=7.12, \mathrm{p}=0.002\right)$ on the accuracy achieved for the TB condition. The post hoc tests with Bonferroni correction show that participants were more accurate on the $\mathrm{X}$ axis (lateral) and on the $\mathrm{Z}$-axis (vertical) than on the $\mathrm{Y}$-axis (depth) ( $\mathrm{p}=0.003, \mathrm{p}=0.02$; respectively).

\subsection{Subjective Evaluation}

Overall, $71 \%$ of the participants preferred the Head-Tracking technique over the Touch-Based technique, and $64 \%$ of them thought that it is easiest to learn. Finally, half of them believe that they performed better with it. Although the scores were higher for HT for all the categories, the Wilcoxon non-parametric tests show no significant effect of the technique for realism and possibility to navigate/ manipulate, and only a marginal effect on ownership $(\mathrm{Z}=-1.72, \mathrm{p}=0.08)$ and agency $(\mathrm{Z}=-1.86, \mathrm{p}=0.06)$.

\section{Discussion And Conclusion}

Following an iterative design approach, we have designed two navigation techniques for our biopsy VR simulator. They were inspected using the FIFA framework to characterize their levels of interaction fidelity. We have used this framework for the first time here for the specific field of VR surgical simulators.

Our results suggest that the higher fidelity navigation technique permits to perform the needle insertion task significantly faster than the moderate fidelity. Not surprisingly, head-tracking technique reported to be easier to learn, and was preferred over the touch-based technique. This can be attributed to its higher level of biomechanical symmetry.

Besides, this technique seems to generate a greater feeling of ownership and agency although the differences were not significant as compared with the moderate fidelity technique. This can be attributed to the higher control symmetry level that it has over touch-based navigation. The results show also that this technique allows the users to perform the task more accurately although no significant difference was found.

Taken together, our findings suggest that the higher fidelity technique is more suited as a navigation technique for the needle insertion virtual trainer. Indeed, in addition to being the closest in terms of interaction to what trainees should perform during the real biopsy task (high interaction fidelity), it allows them to have the best performance and the best user experience. This is an important finding that suggests that higher interaction fidelity is important to increase the performance in VR surgical simulators. However, it is important in the future to show whether this technique is also better suited for knowledge transfer to the real world task. This will further demonstrate the importance of interaction fidelity in the design of VR surgical simulators.

\section{REFERENCES}

[1] A. Chellali, H.M. Mentis, A. Miller, W. Ahn, V.S. Arikatla, G. Sankaranarayanan, S. De, S.D. Schwaitzberg, and C.G.L. Cao. Achieving Interface and Environment Fidelity in the Virtual Basic Laparoscopic Surgical Trainer. International Journal of Human Computer Studies, vol. 96, pp. 22-37, 2016.

[2] Y. Guiard. Asymmetric Division of Labor in Human Skilled Bimanual Action: The Kinematic Chain as a Model. Journal of Motor Behavior, vol. 19, no. 4, pp. 486-517, 1987.

[3] C.J. Hamblin. Transfer of training from virtual reality environments. Wichita State University, Wichita, KS, USA, 2005.

[4] H. Kim, D. Rattner, and M. Srinivasan. The role of simulation fidelity in laparoscopic surgical training. In the proceedings of the 6th International Conference on Medical Imaging Computing and Computer-Assisted Intervention. pp. 1-8, 2003.

[5] D. Liu, N.D. Macchiarella, E.L. Blickensderfer, and D.A. Vincenzi. Transfer of Training. In Hancock, P.A. et al., eds., Human Factors in Simulation and Training. CRC Press, Boca Raton, FL, 2008.

[6] R.P. McMahan. Exploring the Effects of Higher-Fidelity Display and Interaction for Virtual Reality Games. Virginia Polytechnic Institute and State University, Blacksburg, VA, 2011.

[7] D.V. Nguyen, S., Ben Lakhal, A., Chellali, Preliminary Evaluation of a Virtual Needle Insertion Training System. In the proceedings of IEEE VR 2015, pp. 247-248, 2015.

[8] E.D. Ragan, D.A Bowman, R. Kopper, C. Stinson, S. Scerbo, and R.P. McMahan. Effects of Field of View and Visual Complexity on Virtual Reality Training Effectiveness for a Visual Scanning Task. IEEE Transactions on Visualization and Computer Graphics, vol. 21, no. 7, pp. $794-807,2015$.

[9] A. Ricca, and A. Chellali. Fidélité d'interaction dans les simulateurs: deux techniques de navigations pour un simulateur virtuel de biopsie. In the proceedings of IHM' 2016, pp. 278-284, 2016, ACM.

[10] K.E. Roberts, R.L. Bell, and A.J. Duffy. Evolution of surgical skills training. World Journal of Gastroenterology, vol. 12, no. 20, pp. 3219-3224, 2006.

[11] T.A. Stoffregen, B.G. Bardy, L.J. Smart, and R. Pagulayan. On the nature and evaluation of fidelity in virtual environments. In Hettinger, L.J. and Haas, M.W., eds., Virtual and Adaptive Environments. Lawrence Erlbaum Associates, Mahwah, NJ, 2003. 